\title{
Docosahexaenoic Acid Modulates a HER2-Associated Lipogenic Phenotype, Induces Apoptosis, and Increases Trastuzumab Action in HER2-Overexpressing Breast Carcinoma Cells
}

\author{
Graziela Rosa Ravacci, ${ }^{1,2,3}$ Maria Mitzi Brentani, ${ }^{2,3}$ \\ Tharcisio Citrângulo Tortelli, ${ }^{4}$ Raquel Suzana M. M. Torrinhas, ${ }^{1}$ Jéssica Reis Santos, ${ }^{1}$ \\ Angela Flávia Logullo, ${ }^{5}$ and Dan Linetzky Waitzberg ${ }^{1}$ \\ ${ }^{1}$ Department of Gastroenterology, School of Medicine, University of São Paulo, LIM 35, Avenida Doutor Arnaldo 455, \\ Cerqueira Cesar, 01246-903 São Paulo, SP, Brazil \\ ${ }^{2}$ Department of Radiology and Oncology, School of Medicine, University of São Paulo, São Paulo, SP, Brazil \\ ${ }^{3}$ Support Group for Research on Food and Nutrition (NAPAN), University of São Paulo, São Paulo, SP, Brazil \\ ${ }^{4}$ Cancer Institute of State of São Paulo (ICESP), São Paulo, SP, Brazil \\ ${ }^{5}$ Pathology Department, São Paulo Federal University (UNIFESP-EPM), São Paulo, SP, Brazil
}

Correspondence should be addressed to Graziela Rosa Ravacci; grazielametanutri@gmail.com

Received 9 June 2015; Revised 11 September 2015; Accepted 11 October 2015

Academic Editor: Christopher M. Butt

Copyright (C) 2015 Graziela Rosa Ravacci et al. This is an open access article distributed under the Creative Commons Attribution License, which permits unrestricted use, distribution, and reproduction in any medium, provided the original work is properly cited.

In breast cancer, lipid metabolic alterations have been recognized as potential oncogenic stimuli that may promote malignancy. To investigate whether the oncogenic nature of lipogenesis closely depends on the overexpression of HER2 protooncogene, the normal breast cell line, HB4a, was transfected with HER2 cDNA to obtain HER2-overexpressing HB4aC5.2 cells. Both cell lines were treated with trastuzumab and docosahexaenoic acid. HER2 overexpression was accompanied by an increase in the expression of lipogenic genes involved in uptake (CD36), transport (FABP4), and storage (DGAT) of exogenous fatty acids (FA), as well as increased activation of "de novo" FA synthesis (FASN). We further investigate whether this lipogenesis reprogramming might be regulated by mTOR/PPAR $\gamma$ pathway. Inhibition of the mTORC1 pathway markers, p70S6 K1, SREBP1, and LIPIN1, as well as an increase in DEPTOR expression (the main inhibitor of the mTOR) was detected in HB4aC5.2. Based on these results, a PPAR $\gamma$ selective antagonist, GW9662, was used to treat both cells lines, and the lipogenic genes remained overexpressed in the HB4aC5.2 but not HB4a cells. DHA treatment inhibited all lipogenic genes (except for FABP4) in both cell lines yet only induced death in the HB4aC5.2 cells, mainly when associated with trastuzumab. Neither trastuzumab nor GW9662 alone was able to induce cell death. In conclusion, oncogenic transformation of breast cells by HER2 overexpression may require a reprogramming of lipogenic genetic that is independent of mTORC1 pathway and PPAR $\gamma$ activity. This reprogramming was inhibited by DHA.

\section{Introduction}

Cell lipogenic metabolism has traditionally been considered a minor anabolic energy-storage pathway, yet its role in various cancers is increasingly being recognized [15]. Endogenous fatty acid (FA) biogenesis may constitute an oncogenic stimulus that drives normal epithelial cells towards malignancy [1-5]. Moreover, emerging evidence indicates that the oncogenic nature of human lipogenesis depends on the activity and/or expression of key protooncogenes, such as human epidermal growth factor receptor 2 (HER2) $[1,2,5]$. Amplification and overexpression of HER2 are detected in approximately $20-30 \%$ of breast carcinomas and are associated with a poor prognosis [6-10]. Hyperactivation of HER2 promotes aberrant cell proliferation and tumorigenesis, thereby making HER2 
an important therapeutic target against breast cancer [610].

Currently, the primary treatment for HER2-overexpressing tumors is trastuzumab (Herceptin) [11-14]. Trastuzumab is a monoclonal antibody that is designed to target the extracellular domain of HER2 and block its function. However, response rates for trastuzumab monotherapy have been reported to range from $12 \%$ to $34 \%$ with a median duration of 9 months $[9,10]$. Thus, it appears that the mechanism of action of HER2 is not yet fully understood.

We previously showed that HER2 hyperactivation and signaling in breast cancer cells depend strongly on the location of the receptor within membrane lipid rafts [15]. In breast cancer cells, HER 2 overexpression may be accompanied by an increase in cell membrane lipid raft microdomains, thereby establishing a vicious cycle of aberrant cell signaling $[1,15]$. Recent experimental evidence revealed that the dimerization of HER2 (as a homo- or heterodimer with members of its own family) is associated with lipid rafts $[1,16]$. In addition, HER2mediated proliferation and survival signals depend on the colocalization of HER2 with other membrane proteins (e.g., integrins and extranuclear factor of the estrogen receptor [ER]) in lipid rafts $[17,18]$. Accordingly, it is possible that an increase in the number of lipid rafts in HER2-overexpressing cells can enhance the activation of these oncogenic receptors [15].

To ensure lipid raft synthesis, HER2 promotes the activation of fatty acid synthase (FASN). Its final product, palmitate, is frequently used to synthesize membrane microdomains $[1,15,19]$. In a previous study, when this pathway was inhibited by omega-3 docosahexaenoic fatty acid (DHA), lipid rafts were disrupted and cell apoptosis was induced [15]. Thus, HER2 overexpression in breast cancer cells is associated with constitutive upregulation of the endogenous FASN-catalyzed biogenesis of palmitate. The upregulation of palmitate biogenesis represents a "lipogenic benefit" for the proliferation and survival of breast cancer cells by providing lipid raft components for the proper localization and activation of HER2 in the cell membrane $[1,2,15,19]$. However, accumulation of palmitate in nonadipose tissue promptly stimulates lipolysis and apoptosis and can act as an inhibitory feedback signal for endogenous FA synthesis [1, 2, 20-22].

On the other hand, these events seem to be avoided in HER2-overexpressing breast carcinoma cells, through the conversion and storage of FAs as triglycerides by peroxisome proliferator-activated receptor gamma $(\operatorname{PPAR} \gamma)[1,2]$. Rather than preventing lipotoxicity, the transcriptional activation of PPAR $\gamma$ increase the expression of genes related to uptake and transport of exogenous FA, contributing to the establishment of lipogenic phenotype in HER2-overexpressing cells $[1,2]$. Therefore, in these cells, upregulation of FASN appears to be a downstream manifestation of an early and common deregulation of upstream regulatory circuits that affect the lipogenic genetic program [2]. It is believed that the regulation of lipogenesis occurs through mTOR protein $[1,2]$. The HER2/mTOR pathway results in SREBP1 activation which can increase the transcription of PPAR $\gamma$ endogenous ligands and regulates the expression of FASN $[1,2]$. However, the details of this process remain unclear, since activation of components of the mTOR pathway, as mTORC1, may limit the survival signs by reducing Akt activity $[1,2]$. Accordingly, it remains to be determined whether HER2 overexpressionmediated oncogenic transformation requires the activation of a genetic switch of lipogenic cell metabolism to maintain aberrant signaling that affects cell survival and proliferation.

From a molecular perspective, we hypothesized that the HER2 overexpression-mediated oncogenic transformation of breast cells involves a distinct lipogenic program that, in addition to FA synthesis, requires the coordinated expression of genes involved in the following: (a) the conversion and storage of excess FAs (e.g., palmitate) to triglycerides, thereby avoiding lipotoxicity; and (b) the uptake and transport of other exogenous FAs, which are necessary to maintain a constant supply of lipids/lipid precursors, membrane lipid raft production, and lipid-based posttranslational protein modifications in these highly proliferative cells. From a clinical perspective, the dependence of cancer cells on lipogenesis for survival and proliferation may represent the "Achilles' heel" of HER2-driven oncogenesis. Thus, lipogenic enzyme inhibitors, modulators of PPAR $\gamma$ transcriptional activity, and, perhaps, dietary omega-3 polyunsaturated FAs (e.g., DHA) may provide novel therapeutic strategies for the clinical management of HER2-positive breast carcinomas and may increase the efficacy of standard therapies [2, 20, 21].

DHA is a potent PPAR $\gamma$ regulator that has been shown to suppress adiposity in rodents and block adipogenesis in many adipocyte cell lines $[23,24]$. As a modulator of cell membrane lipid composition, DHA can disrupt lipid rafts, thereby impairing HER2-regulated pathways and inducing cell apoptosis [15]. Therefore, our second hypothesis was that DHA could effectively modulate the lipogenic genetic switch associated with HER2 overexpression. In addition, we investigated whether DHA increases the trastuzumab action in HER2-overexpressing breast carcinoma cells.

\section{Methods and Materials}

2.1. Cell Culture. Parental, nontransformed HB4a cells and HER2-overexpressing HB4a variant cells, HB4aC5.2, were cultured in RPMI-1640 with 10\% fetal bovine serum (FBS) (GIBCO, Invitrogen, Brazil) plus ampicillin, hydrocortisone, and insulin (Sigma-Aldrich, Brazil) at $37^{\circ} \mathrm{C}$ in a $10 \% \mathrm{CO}_{2}$ humidified incubator $[25,26]$. HB4a cells were derived from normal breast luminal cells. HB4aC5.2 cells were generated by cotransfecting HB4a cells with pJ5E.c-erbB-2, a plasmid containing the full-length normal human HER2 cDNA, derived from the established breast cancer line BT474, under the control of the mouse mammary tumor viruslong terminal repeat (MMTV-LTR) promoter and SV40 polyadenylation signals $[25,26]$. Five copies of pJ5E.c-erbB2 were detected in the genome of the $\mathrm{C} 5.2$ clone, resulting in the expression of $\sim 10^{6}$ HER 2 receptors per HB4aC5. 2 cell $[25,26]$. Cells were tested periodically for mycoplasma (data not shown) and were authenticated by real-time reverse transcription polymerase chain reaction (RT-PCR) to evaluate HER2 overexpression $[15,25,26]$. The HB4a and HB4aC5.2 cell lines were a generous gift from Michael J. O’Hare (Ludwig 
TABLE 1: Primers used for RT-PCR.

\begin{tabular}{lll}
\hline GENE & Forward $\left(5^{\prime}-3^{\prime}\right)$ & Reverse $\left(5^{\prime}-3^{\prime}\right)$ \\
\hline HER $2 /$ neu & GGGCTGGCCCGATGTATTTGAT & ATAGAGGTTGTCGAAGGCTGGGC \\
FAT $\mathrm{CD} 36$ & TGCAAAACGGCTGCAGGTCA & TGGTTTGTGCTTGAGCCAGGTTTAT \\
$D G A T$ & GGAGTGGGCTTTGCCACCAGG & CGCCTTTCATGACGCATTCCACC \\
$D E P T O R$ & TCGCCTGCAGGATTCTTTAT & GCATCACCACACACCAGTTC \\
SREBP1 & GCGGAGCTGCCCCGAACAAA & GTGCAGCCTGAGCCGTAGCTG \\
FASN & ACAGTGACTTCCCTCGCCTAT & GCATGGACGGCTACATCTTCAA \\
UBC & CCGAGACACTCGTGGGCTA & CTTCAGCAGGACATTGATGCC \\
HMBS & ACCCAAGAAAAGCACAAGG & AGCCCAGTGTTACCACCAAG \\
\hline
\end{tabular}

Institute for Cancer Research and University College London Breast Cancer Laboratory, Department of Surgery, London, $\mathrm{UK})$.

2.2. Cell Treatments. Briefly, cells were seeded in flasks with medium containing 10\% FBS and were allowed to adhere. After $24 \mathrm{~h}$, the culture medium was replaced with fresh medium containing $10 \%$ FBS plus treatment agent. Cells were incubated for $72 \mathrm{~h}$ without changing the medium. Then, the cells were harvested with trypsin-EDTA (Sigma-Aldrich), and the viable cells were counted by Trypan Blue exclusion (Sigma-Aldrich) and a hemocytometer. Only samples with more than $95 \%$ viable cells were used.

2.2.1. Treatment with the PPAR Inhibitor GW9662. The HB4a and HB4aC5.2 cell lines were treated with GW9662 diluted in dimethyl sulfoxide (DMSO) to $1 \mu \mathrm{L} / \mathrm{mL}$, on the basis of previous experimental studies using breast cancer cells [27]. The final concentration of DMSO did not exceed $0.1 \%$ in any case and was not cytotoxic in any of the cell lines tested at this concentration. GW9662 was kindly provided by Professor William Festuccia (University of Sao Paulo, Brazil).

2.2.2. Treatment with Trastuzumab. The $\mathrm{HB} 4 \mathrm{a}$ and HB4aC5.2 cell lines were treated with trastuzumab diluted in phosphate-buffered saline (PBS) to a concentration of $15 \mu \mathrm{g} / \mathrm{mL}$, on the basis of previous experimental and clinical studies [11-14]. Trastuzumab (Herceptin/Genentech, EUA) was kindly provided by Professor José Ernesto Belizário (University of Sao Paulo, Brazil).

2.2.3. Treatment with DHA. DHA (C22:6n-3, Sigma-Aldrich) was dissolved in ethanol prior to emulsification in medium containing serum proteins. The final concentration of ethanol in the culture medium did not exceed $0.05 \%$. This concentration was previously shown to be nontoxic to cells $[28,29]$. The HB4a and HB4aC5.2 cell lines were treated with $100 \mu \mathrm{M}$ DHA for $72 \mathrm{~h}$, based on previous testing of both cell lines with varying doses of DHA $(25,50,75$, and $100 \mu \mathrm{M}$ DHA for 24 , 48 , and $72 \mathrm{~h}$ in standard medium). Standard medium plus ethanol was used as a control.
2.3. Proliferation Experiments. To compare proliferation rates between the HB4a and $\mathrm{HB} 4 \mathrm{aC} 5.2$ cell lines, $10^{3}$ cells were plated in triplicate and were allowed to attach to 96-well plates overnight in culture medium. The following day, the cells were washed with PBS and received fresh culture medium. After $5 \mathrm{~d}$, the cells were harvested and combined with $0.5 \mathrm{mg} / \mathrm{mL}$ MTT. Four hours later, solubilization buffer was added and the cells were incubated for an additional $15 \mathrm{~h}$. Spectrophotometry of the cells was then performed at $595 \mathrm{~nm}$ with a $655 \mathrm{~nm}$ reference filter. Calibration curves were established with a known number of cells, allowing the absorbance values to be converted into cell numbers.

To compare proliferation rates between treatments, cells were washed with PBS and received culture medium containing trastuzumab or GW9662 for $72 \mathrm{~h}$. At several time points during this $72 \mathrm{~h}$ incubation (e.g., baseline and $12,24,48$, and $72 \mathrm{~h}$ after treatment), a portion of the cells were harvested and combined with $0.5 \mathrm{mg} / \mathrm{mL}$ MTT to assess proliferation. Detection of proliferation was performed as described above.

2.4. RT-PCR. Total RNA was extracted from cells with the RNeasy Mini Kit (Qiagen, Brazil), in accordance with the manufacturer's instructions. RNA concentration and purity were determined with a spectrophotometer (NanoDrop ND1000 UV-Vis Spectrophotometer, NanoDrop Technologies) by calculating the ratio of optical density at wavelengths of $260 \mathrm{~nm}$ and $280 \mathrm{~nm}$. The cDNA was synthesized by reverse transcription from $2 \mu \mathrm{g}$ of RNA with the Superscript III Reverse Transcriptase Kit (Invitrogen, Brazil), according to the manufacturer's instructions.

Each PCR sample included $2.5 \mu \mathrm{L}$ of cDNA, $5 \mu \mathrm{L}$ of SYBR Green I (Molecular Probes), $1.1 \mu \mathrm{L}$ of $\mathrm{MgCl}_{2}, 0.9 \mu \mathrm{L}$ of $\mathrm{H}_{2} \mathrm{O}$ DEPC, and $0.5 \mu \mathrm{L}$ of primers specific for the gene of interest (Table 1). PCR samples were amplified using a Rotor Gene 3000 System. After each run, the melting curve was analyzed to assess the reaction specificity.

2.5. Western Blotting. The HB4a and $\mathrm{HB} 4 \mathrm{aC} 5.2$ cell lines $\left(10^{5}\right.$ cells $/ 25 \mathrm{~cm}^{2}$ flask) were treated with $5 \mathrm{~mL}$ of medium containing $10 \%$ FBS, with or without DHA or trastuzumab. After $72 \mathrm{~h}$, the cells were pelleted and proteins were extracted in a lysis buffer containing $50 \mathrm{mM}$ Tris- $\mathrm{HCl}$ (pH 7.4), $150 \mathrm{mM}$ $\mathrm{NaCl}, 1 \% \mathrm{NP}-40,0.5 \%$ sodium deoxycholate, $0.1 \%$ sodium 
dodecyl sulfate (SDS), and protease inhibitors. Protein concentrations were determined with the Bradford assay. Cell lysates $(40 \mu \mathrm{g})$ were boiled for $5 \mathrm{~min}$ in Laemmli buffer before being loaded on $10 \%$ acrylamide gels for SDS-polyacrylamide gel electrophoresis. Separated proteins were transferred to nitrocellulose membranes. The FASN protein was separated on a $6 \%$ acrylamide gel. Membranes were blocked for $1 \mathrm{~h}$ in Tris-buffered saline containing 0.05\% Tween-20 and 5\% skim milk before being incubated with primary antibodies (Cell Signaling Technology, USA, 1:1000). After $16 \mathrm{~h}$ at $4^{\circ} \mathrm{C}$, membranes were incubated with anti-rabbit IgG antibodies $(1: 5000)$. Bound antibodies were visualized by enhanced chemiluminescence reagent (GE). Membranes were subjected to autoradiography, and quantitative densitometric analysis was performed with the Scion Image software package.

2.6. Flow Cytometry Analysis of Cell Death. The HB4a and HB4aC5.2 cell lines $\left(10^{5}\right.$ cells $/ 25 \mathrm{~cm}^{2}$ flask) were treated with $5 \mathrm{~mL}$ of medium containing $10 \%$ FBS, with DHA, trastuzumab, GW9662, or DHA plus trastuzumab, for $72 \mathrm{~h}$. Treated cells were fixed in $70 \%$ ethanol at $-20^{\circ} \mathrm{C}$ and stained for $30 \mathrm{~min}$ at room temperature with $20 \mu \mathrm{g} / \mathrm{mL}$ propidium iodide (PI) (Sigma-Aldrich), Triton-X (0.1\% v/v), and $200 \mu \mathrm{g} / \mathrm{mL}$ DNase-free RNase diluted in PBS. Cells from each sample were analyzed for DNA content with a Becton Dickinson FACS Caliber instrument. Percentages of cells in the sub-G1, G0/G1, and S/G2/M phases of the cell cycle were determined with the Cell Quest software package. Cell death was measured according to the percentage of cells in the sub-G1 region of the fluorescence scale that contained hypodiploid DNA.

2.7. Statistical Analysis. Data are presented as mean \pm standard error of the mean (SEM) of three independent experiments performed for each variable. For both cell lines, relative gene expression was expressed as the ratio between target gene expression and the mean expression of the constituent genes (i.e., $U B C, H M B S$, and $\beta$-actin, selected because they did not present significant variations in expression between the untreated and treated cell lines). For comparisons between cell lines, gene expression values obtained by real-time PCR were normalized to the results obtained from the HB4a cell line. For comparisons between treatments, gene expression values obtained by real-time PCR were normalized to results obtained from cell lines treated with ethanol, DMSO, or PBS (controls [CNTs]). Data were obtained from experiments performed in quadruplicate (or duplicate, for real-time PCR assays). The statistical significance of differences was assessed by one-way analysis of variance (ANOVA), followed by the Bonferroni post-test. The significance level was set at $P \leq 0.05$.

\section{Results}

3.1. In HB4aC5.2 Cells, HER2 Overexpression Is Associated with Activation of a Lipogenic Genetic Switch. To test the hypothesis that HER2 overexpression requires activation of a lipogenic genetic program for oncogenic transformation, the immortalized human mammary luminal epithelial cell line, $\mathrm{HB} 4 \mathrm{a}$, was transfected with HER2 cDNA to generate the HB4aC5.2 cell line. Oncogenic transformation was assessed by RT-PCR. The HB4aC5.2 cell line expressed HER2 mRNA at levels equivalent to the tumor-derived cell line, SKBR3, but should be identical to the HB4a cell line in all other aspects (including ER mRNA levels) (Figure 1(a)). The ER-negative SKBR3 cell line is characterized by HER2 amplification.

Real-time PCR analysis detected increased expression of lipogenic genes related to FA uptake (fatty acid translocase gene/cluster of differentiation 36, FAT/CD36), FA transport (fatty acid binding protein $4, F A B P 4$ ), and lipid storage (diacylglycerol acyltransferase, DGAT) in HB4aC5.2 cells compared to HB4a cells (Figure 1(b)). Interestingly, FASN expression was not altered by HER2 overexpression (Figure 1(b)). However, according to Western blot analysis, HB4aC5.2 cells exhibited increased activation of the FASN protein compared to HB4a cells (Figure 1(c)).

3.2. DEPTOR, but Not mTOR/PPAR, , May Be Associated with Activation of a Lipogenic Genetic Program in HB4aC5.2 Cells. Activation of mTOR pathway components, mainly complex 1 (mTORC1) and the p70S6K1 (p70 ribosomal S6 kinase 1) protein, and expression of SREBP1 (sterol regulatory element-binding protein 1) and LIPIN1 may contribute to lipogenesis by promoting the production of endogenous ligands for PPAR $\gamma[2,30,31]$. Unexpectedly, both RTPCR (Figure 2(a)) and Western blotting (Figure 2(b)) assays showed that all of these mTORC1 pathway markers were decreased in HB4aC5.2 cells, but not in HB4a cells (Figure 2).

When HB4a cells were treated with a PPAR $\gamma$ selective antagonist (GW9662) and RT-PCR assays were performed, all of the PPAR $\gamma$-target regulatory genes via mTORC1 were decreased (with the exception of FAT/CD36, which showed increased expression) (Figure 3). Intriguingly, when HB4aC5.2 cells were treated with GW9662, expression levels of FAT/CD36 increased, but the expression levels of the other genes remained unchanged (Figure 3 ).

Consistent with these findings, an increase in expression of DEPTOR (the main inhibitor of the mTOR pathway) was detected in HB4aC5.2 cells, but not in HB4a cells (Figure 2(a)). When overexpressed, DEPTOR can inhibit the activation of both complexes of the mTOR pathway, but especially mTORC1 [32-35]. The observed downregulation of SREBP1 (Figure 2(a)) and its regulatory protein p70S6K1 (Figure 2(b)) confirmed the inhibition of mTORC1 activation and supported the possibility that DEPTOR activity was increased in $\mathrm{HB} 4 \mathrm{aC} 5.2$ cells.

Although an association between activation of the mTORC1 pathway and cell proliferation has been observed in several cancers, this relationship was not observed in the present study $[31,32,36]$. Instead, the hyperproliferative phenotype induced by HER2 in $\mathrm{HB} 4 \mathrm{aC} 5.2$ cells appeared to be independent of this pathway. The increased rate of proliferation of $\mathrm{HB} 4 \mathrm{aC} 5.2$ cells compared to $\mathrm{HB} 4 \mathrm{a}$ cells was independent of additional mitogen stimulation (Figure 3(b)). Treatment with GW9662 did not affect the proliferation rate of either cell line (Figure 3(c)). 


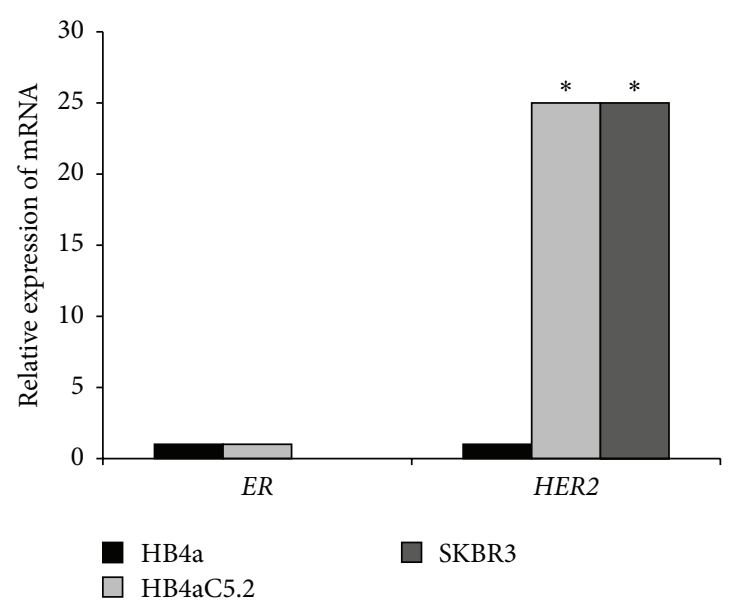

(a)

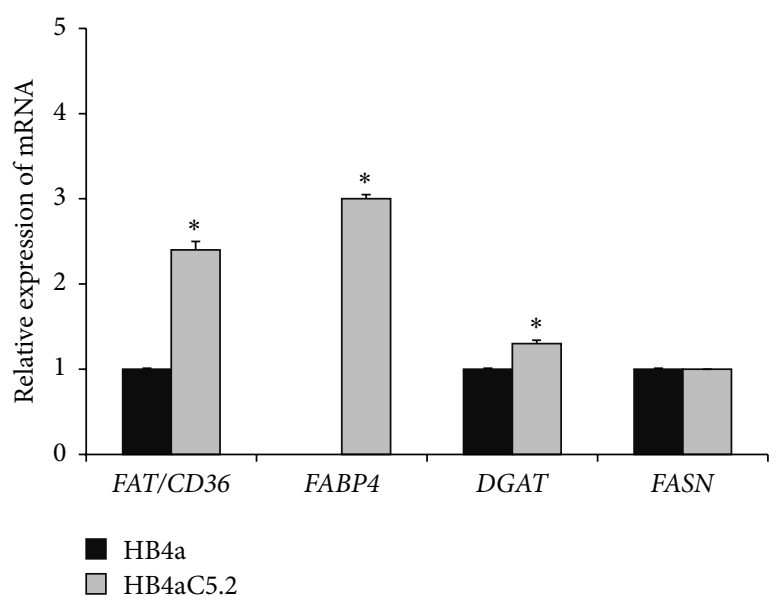

(b)

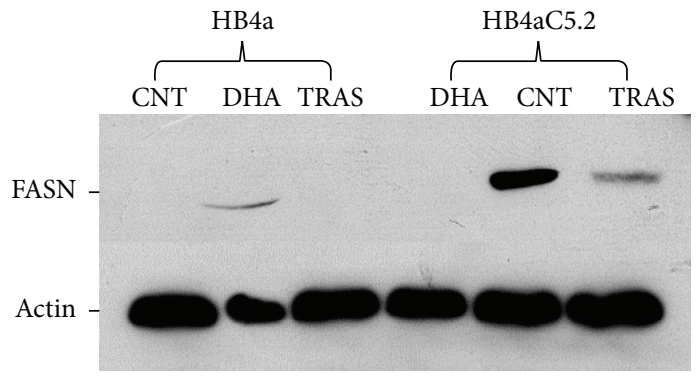

(c)

FIGURE 1: HER2 overexpression and activation of a lipogenic genetic program. (a-b) Relative expression levels of HER2 and ER mRNAs in the HB4a, HB4aC5.2, and SKBR3 cell lines (a) and levels of FAT/CD36, FABP4, DGAT, and FASN mRNAs in the HB4a and HB4aC5.2 cell lines (b). The experiment was performed in quadruplicate. The PCR reaction was performed in duplicate. ${ }^{*} P<0.001$ versus HB4a. (c) Activation of FASN protein in HB4a and HB4aC5.2 cells. Immunoprecipitated proteins were subjected to Western blotting for FASN and $\beta$-actin, as controls. CNT: control cells; DHA: cells treated with $100 \mu \mathrm{M}$ DHA for $72 \mathrm{~h}$; TRAS: cells treated with $15 \mu \mathrm{g} / \mathrm{mL}$ trastuzumab for $72 \mathrm{~h}$.

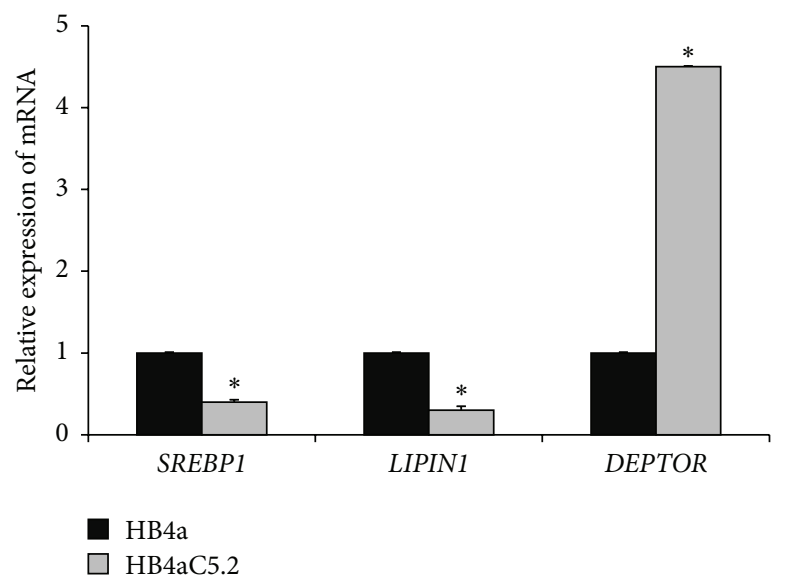

(a)

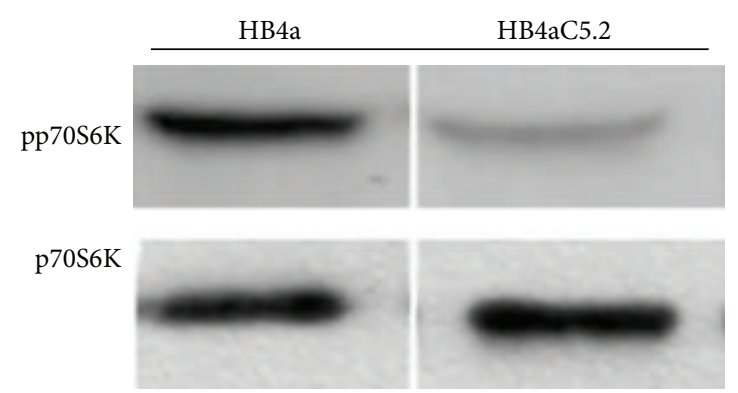

(b)

FIGURE 2: Relative expression of mTORC1 pathway markers. (a) Relative expression of SREBP1, LIPIN1, and DEPTOR in HB4a and HB4aC5.2 lines. Data were obtained from an experiment performed in quadruplicate. The real-time PCR reaction was performed in duplicate. ${ }^{*} P<$ 0.001 versus HB4a. (b) Detection of phosphorylated and nonphosphorylated forms of p70S6K (pp70S6K and p70S6K, resp.) by Western blot in HB4a and HB4aC5.2 cells. 


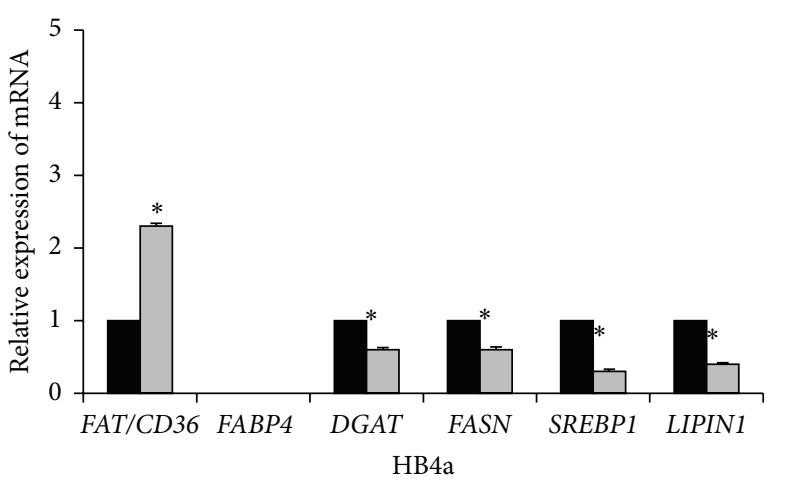

CNT

GW9662
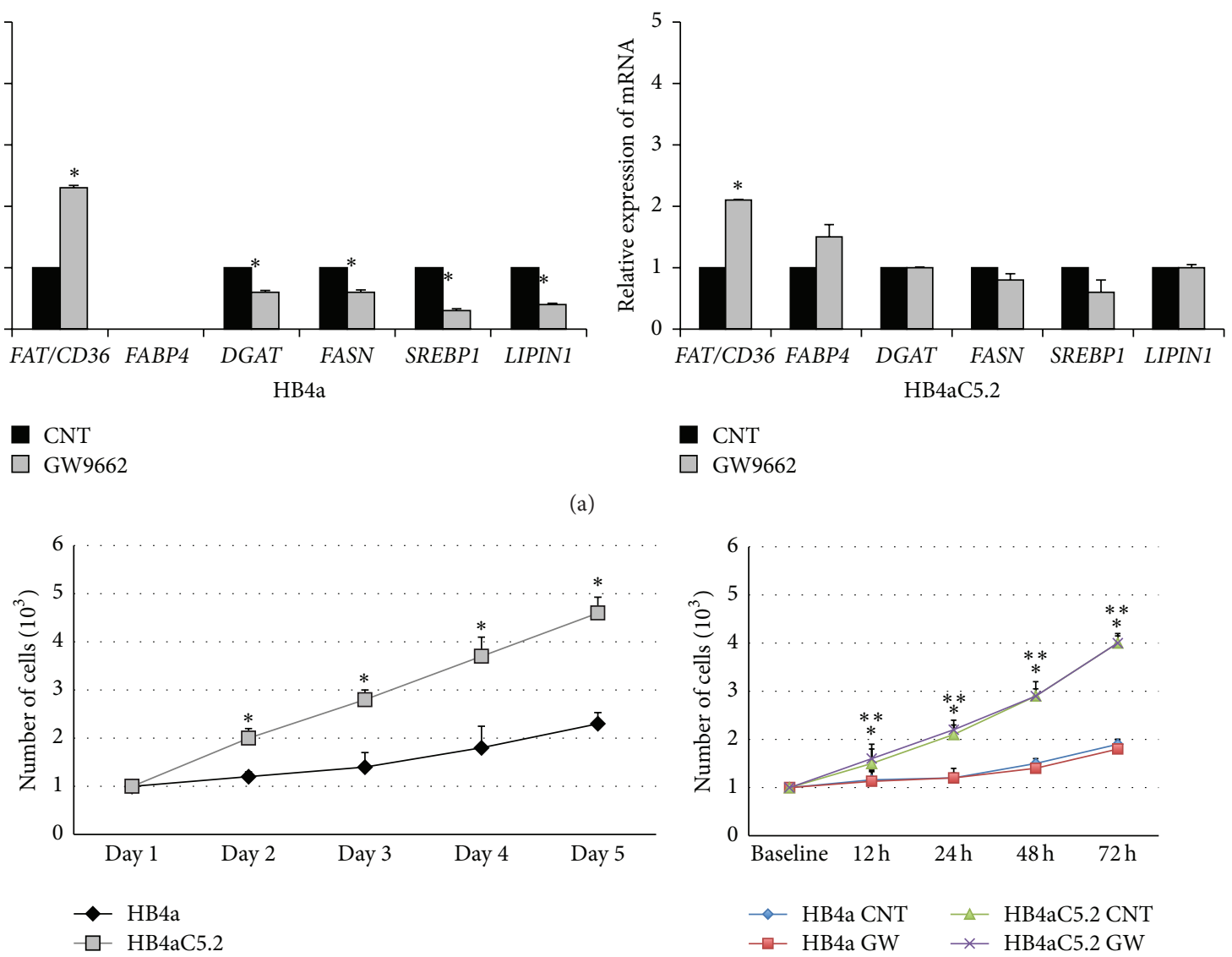

(b)

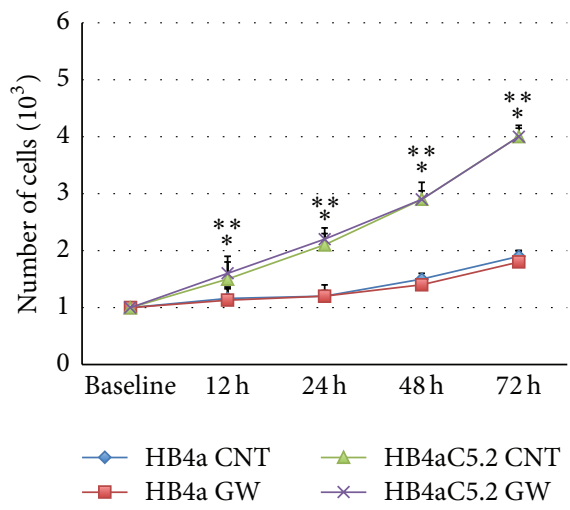

(c)

FIGURE 3: Effects of the PPAR $\gamma$ inhibitor GW9662 on HB4a and Hb4aC5.2 cells. (a) Relative expression of FAT/CD36, FABP4, DGAT, SREBP1, LIPIN1, and FASN in HB4a and HB4aC5.2 cells treated with GW9662 $(1 \mu \mathrm{L} / \mathrm{mL})$ for $72 \mathrm{~h}$. DMSO was used as a control (CNT). Data were obtained from an experiment performed in quadruplicate. The real-time PCR reaction was performed in duplicate. ${ }^{*} P<0.001$ versus CNT. Proliferation rates for untreated (b) and treated (c) HB4a and HB4aC5.2 cells. Untreated cells were cultured in standard medium without additional stimulation for $5 \mathrm{~d}$. Treated cells were incubated with medium containing GW9662 (GW) or DMSO as a control (CNT) for 0, 12, 24, 48, and 72 h. (b) ${ }^{*} P<0.001$ versus HB4a. ${ }^{* *} P<0.001$ versus HB4a CNT. (c) ${ }^{*} P<0.001$ versus HB4aC5.2 CNT. ${ }^{* *} P<0.001$ versus HB4aC5.2 GW.

3.3. In HB4aC5.2 Cells, Trastuzumab Treatment Was Accompanied by Increased FASN Gene Expression and Decreased FASN Protein Activation, While the Cell Proliferation Rate Remained Unchanged. Real-time PCR analyses of FAT/ CD36, FABP4, DGAT, FASN, SREBP1, and LIPIN1 revealed that trastuzumab treatment was associated with a decrease in DGAT mRNA and increases in SREBP1 and FASN mRNA levels in HB4aC5.2 cells (Figure 4(b)). However, these results were not observed in HB4a cells (Figure 4(a)). Moreover, despite the significant increase in FASN transcription that was induced by trastuzumab treatment in $\mathrm{HB} 4 \mathrm{aC} 5.2$ cells, activation of the FASN protein was inhibited in this cell line (Figure 1(c)).

In HB4aC5.2 cells, trastuzumab treatment did not influence cell proliferation, as detected by MTT assays (Figure 4(b)).

3.4. In HB4aC5.2 Cells, DHA Treatment Affected the Activation of a Lipogenic Genetic Program to Induce Cell Death and Improve Trastuzumab Action in Parallel with a Decrease in DEPTOR Transcription. Previous studies have shown that DHA exhibits a triacylglycerol-lowering effect in vitro and in vivo and reduces the expression levels of lipogenic genes $[37,38]$. However, the mechanisms responsible for these effects remain unknown. Real-time PCR analyses of FAT/CD36, FABP4, DGAT, FASN, SREBP1, and LIPIN1 were performed for HB4aC5.2 and HB4a cells, with or without DHA treatment. DHA reduced the expression levels of all of the genes assayed, except $F A B P 4$, and inhibited the activation of FASN in HB4aC5.2 cells (Figure 5). Although both cell lines achieved very similar expression levels for the genes (except FABP4), DHA treatment induced cell death only in HB4aC5.2 cells (Figure 6(a)). Neither trastuzumab nor GW9662 alone affected the rate of cell death for either cell line (Figure 6(a)); however, combined treatment with DHA and trastuzumab increased cell death in the HB4aC5.2 cells when compared with DHA and trastuzumab alone (Figure 6(a)).

Finally, the relative expression of DEPTOR in the HB4a and HB4aC5.2 cells treated with DHA, trastuzumab, DHA plus trastuzumab, GW9662, or culture medium (as a control) 


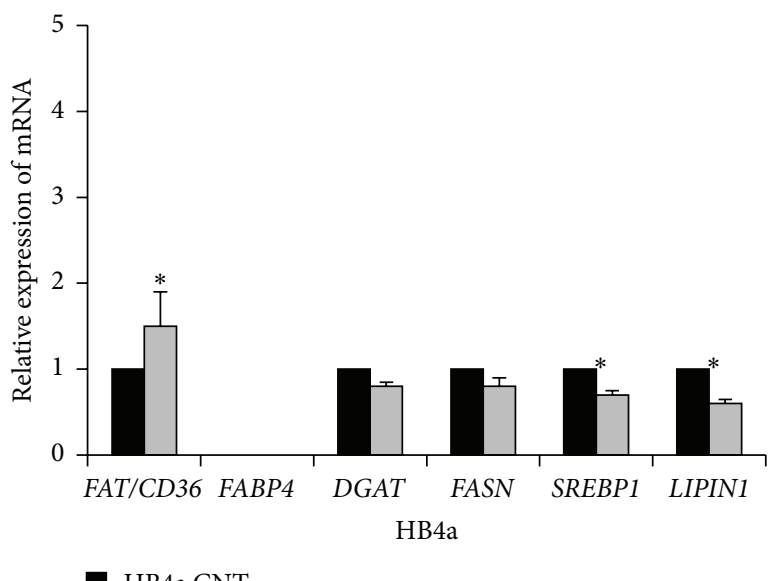

HB4a CNT

HB4a TRAST

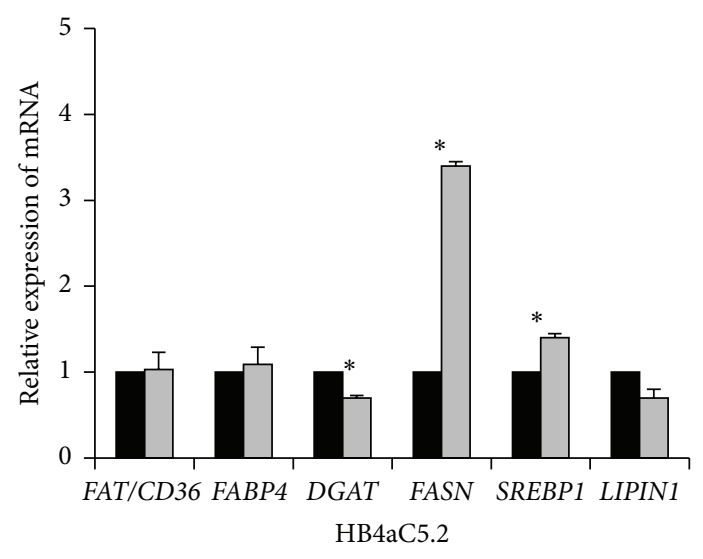

HB4aC5.2 CNT

HB4aC5.2 TRAST

(a)

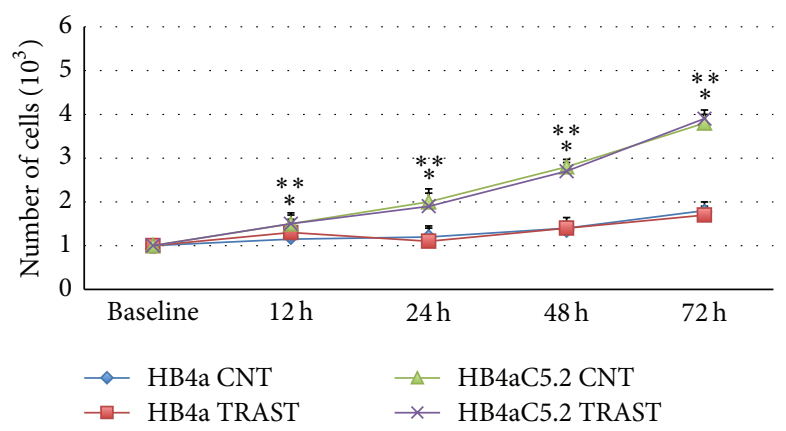

(b)

FIGURE 4: Effect of the HER2 inhibitor trastuzumab on HB4a and Hb4aC5.2 cells. (a) Relative expression of FAT/CD36, FABP4, DGAT, FASN, SREBP1, and LIPIN1 in HB4a and HB4aC5.2 cells treated with trastuzumab (Herceptin, $15 \mu \mathrm{g} / \mathrm{mL}$ for $72 \mathrm{~h}$ ) or PBS as a control (CNT). Data were obtained from an experiment performed in quadruplicate. The real-time PCR reaction was performed in duplicate. ${ }^{*} P<0.001$ versus CNT. (b) Proliferation rates of HB4a and HB4aC5.2 cells treated with trastuzumab (TRAST) or PBS as a control (CNT) for 0, 12, 24, 48, and 72 h. ${ }^{*} P<0.001$ versus HB4aC5.2 CNT. ${ }^{* *} P<0.001$ versus HB4aC5.2 TRAST.

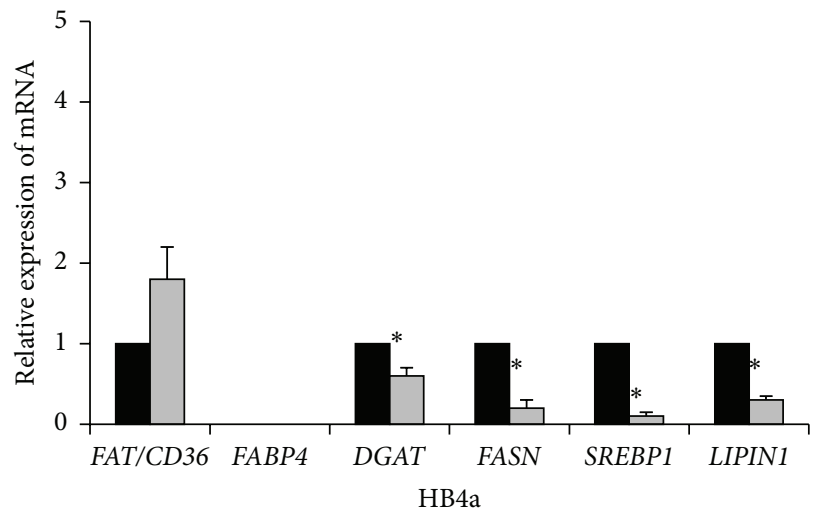

HB4a CNT

HB4a DHA

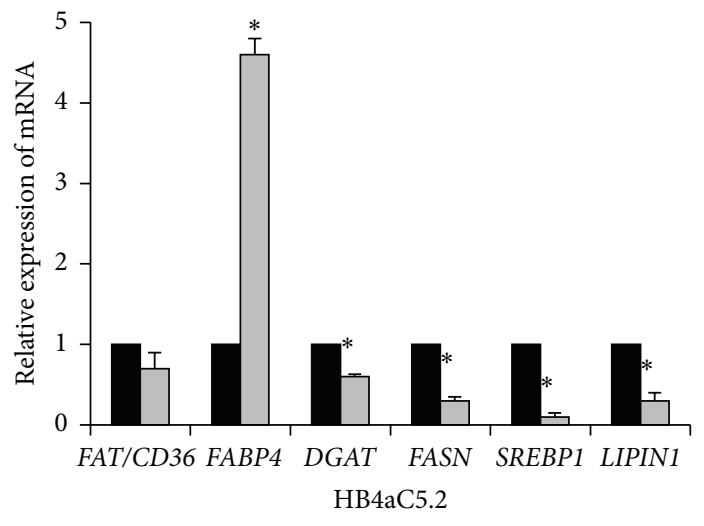

HB4aC5.2 CNT

HB4aC5.2 DHA

FiguRE 5: Effect of DHA on HB4a and Hb4aC5.2 cells. Relative expression of FAT/CD36, FABP4, DGAT, FASN, SREBP1, and LIPIN1 in HB4a and $\mathrm{HB} 4 \mathrm{aC} 5.2$ cells treated with DHA $(100 \mu \mathrm{M}$ for $72 \mathrm{~h})$ or ethanol as a control (CNT). Data were obtained from an experiment performed in quadruplicate. The real-time PCR reaction was performed in duplicate. ${ }^{*} P<0.001$ versus CNT. 


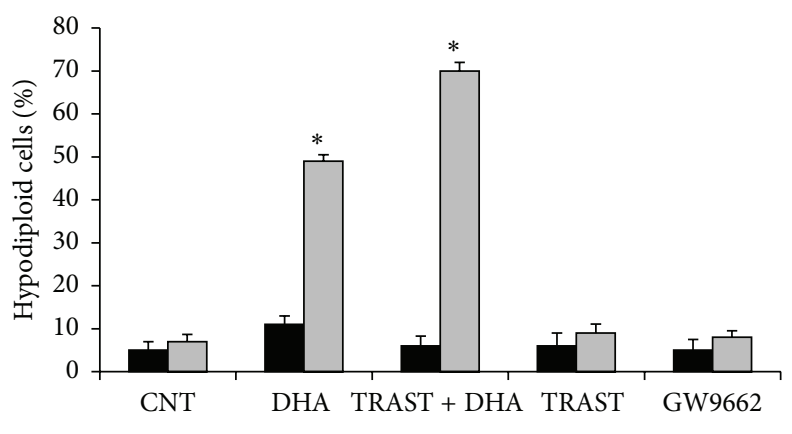

口 HB4a $\square$ HB4aC5.2

(a)
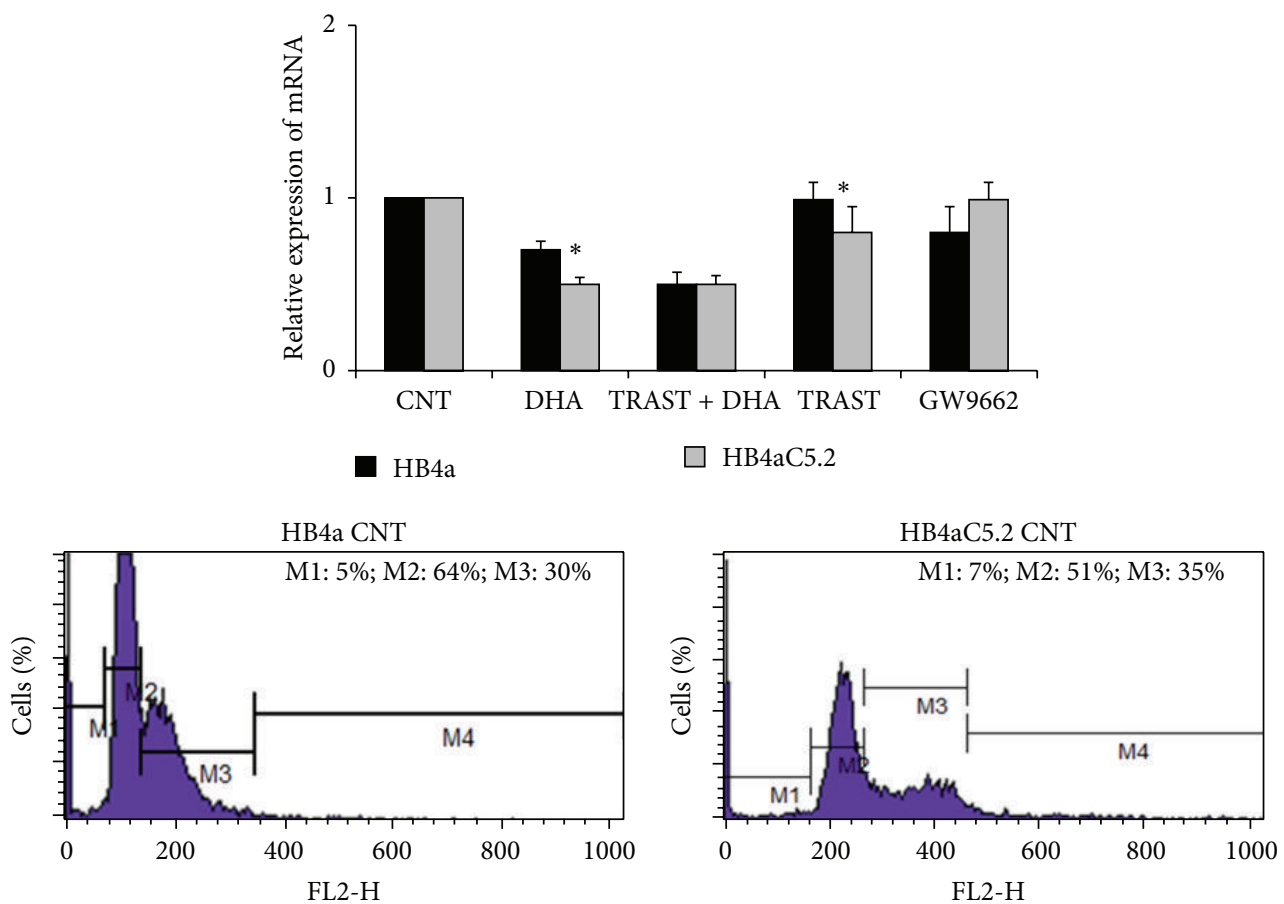

DNA content

HB4a DHA

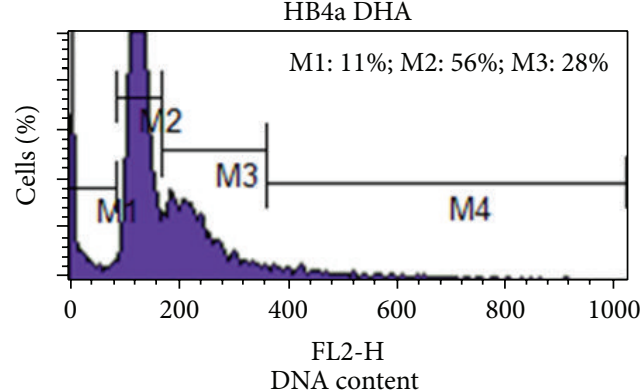

DNA content
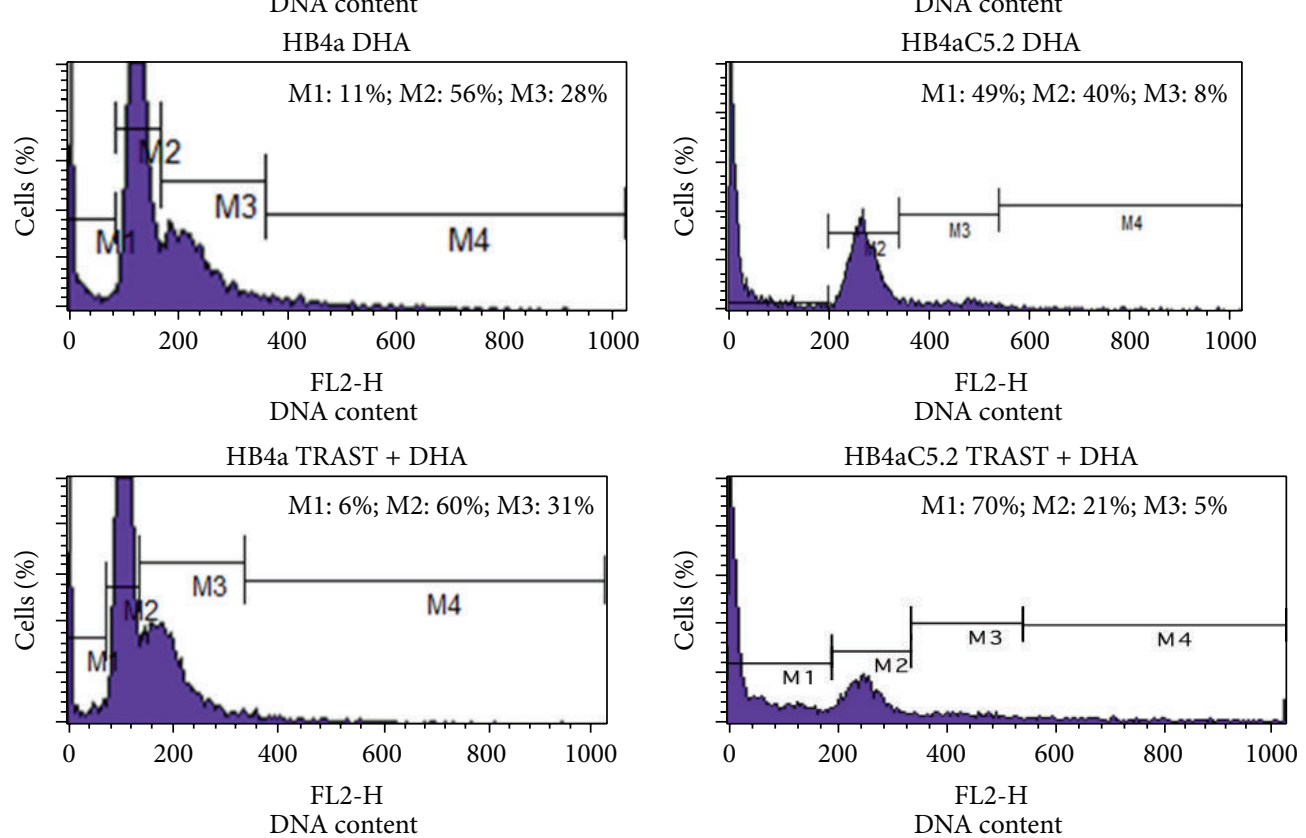

Figure 6: Continued. 

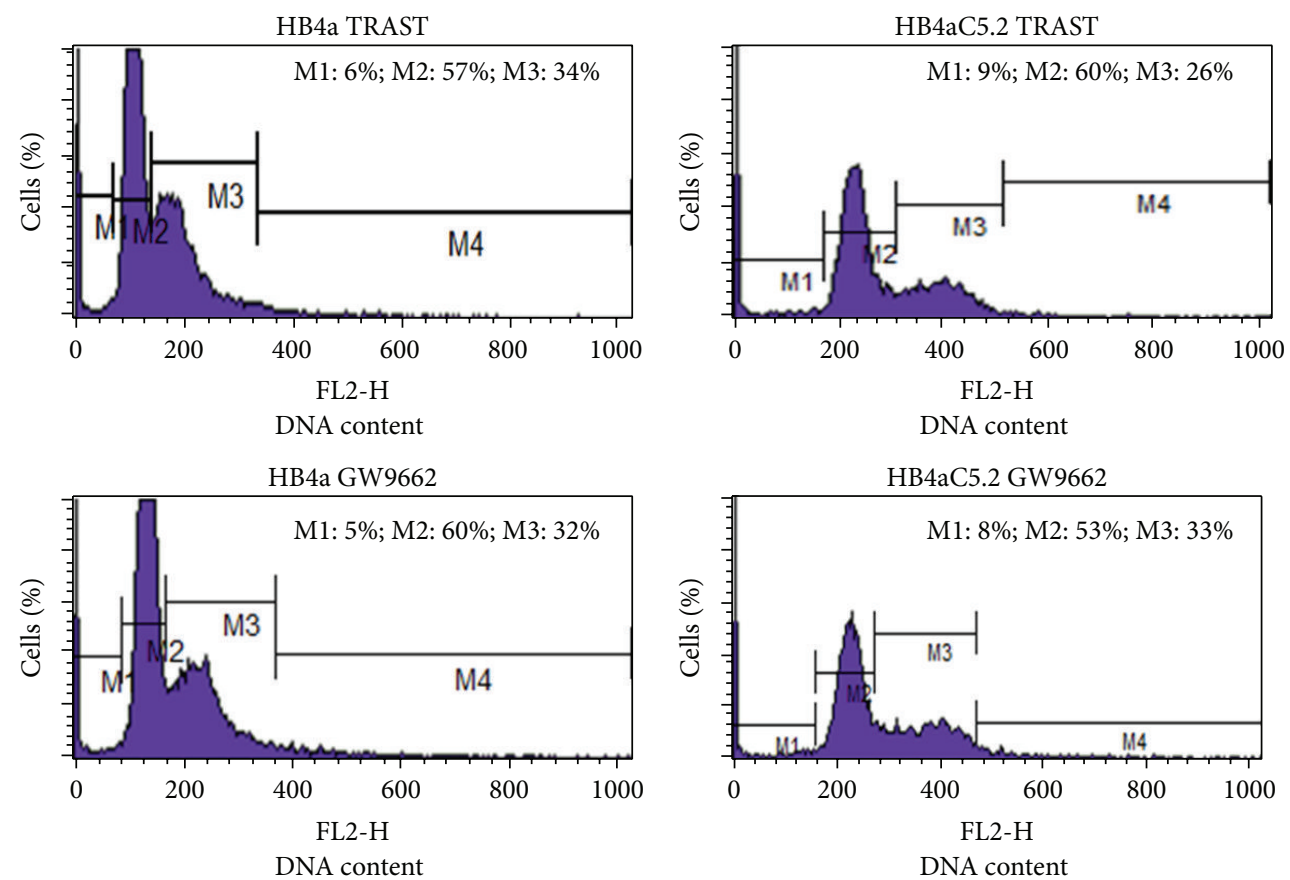

(b)

FIGURE 6: Percentage of cell death induced by different treatments and relative expression of DEPTOR. (a) Percentage of cell death induced by $100 \mu \mathrm{M}$ DHA, $15 \mu \mathrm{g} / \mathrm{mL}$ trastuzumab (TRAST), $15 \mu \mathrm{g} / \mathrm{mL}$ trastuzumab $+100 \mu \mathrm{M}$ DHA, and $1 \mu \mathrm{L} / \mathrm{mL}$ GW9662 for 72 $\mathrm{h}$ in HB4a and HB4aC5.2 cells. Culture medium was used as a control (CNT). Subsequently, all cells were stained with PI and analyzed by flow cytometry. Cells exhibiting hypodiploid DNA content were considered to have undergone cell death. ${ }^{*} P<0.001$ versus HB4a. ${ }^{*} P<0.001$ DHA versus CNT, TRAST + DHA, TRAST, and GW9662. Data were obtained from an experiment performed in triplicate. (b) Relative expression of DEPTOR gene in HB4a and HB4aC5.2 cells treated with $100 \mu \mathrm{M}$ DHA, $15 \mu \mathrm{g} / \mathrm{mL}$ trastuzumab (TRAST), $100 \mu \mathrm{M}$ DHA plus $15 \mu \mathrm{g} / \mathrm{mL}$ trastuzumab (TRAST + DHA), $1 \mu \mathrm{L} / \mathrm{mL}$ GW9662, or culture medium as a control (CNT) for $72 \mathrm{~h}$. Data were obtained from an experiment performed in quadruplicate. The real-time PCR reaction was performed in duplicate. ${ }^{*} P<0.001$ versus CNT. Results from PBS and DMSO treatments (vehicle dilution) did not differ from those obtained from treatment with standard culture medium. The histograms below the graphs represent the data obtained by flow cytometry. M1: percentage of hypodiploid cells (e.g., cell death); M2: percentage of cells in the G0/G1 phase of the cell cycle; M3: percentage of cells in the S/G2/M phase of the cell cycle; and M4: cell debris.

was detected by real-time PCR. In HB4aC5.2 cells, DHAinduced toxicity was accompanied by a decrease in DEPTOR transcription. A greater decrease in DEPTOR transcription was induced by DHA plus trastuzumab treatment compared to treatment with DHA alone (Figure 6(b)).

\section{Discussion}

We hypothesized that the HER2 overexpression-mediated oncogenic transformation of breast cells involves a distinct lipogenic program that, in addition to FA synthesis, requires the coordinated expression of genes involved in the following: (a) the conversion and storage of excess FAs to triglycerides, thereby avoiding lipotoxicity; and (b) the uptake and transport of other exogenous FAs, which are necessary to maintain a constant supply of lipids/lipid precursors, in these highly proliferative cells.

For a model, we chose a transformed, immortalized cell line with a strictly luminal phenotype that has been specifically engineered to overexpress HER2 (HB4aC5.2) but is identical to its parental strain (HB4a) in all other aspects. This permits a cleaner analysis of the specific effects of enhanced HER2 levels on luminal epithelial cell function and phenotype, unlike most tumor cell lines already established and described in in vitro studies, which show multiple genetic aberrations other than overexpression of HER2 receptors. By using HB4aC5.2 and HB4a cells, we were able to analyze the specific effects that enhancing HER2 levels had on the lipogenic phenotype $[25,26]$.

Elevated levels of HER2 expression have been observed in human breast cancers, with levels of HER2 amplification ranging from 2 -fold to greater than 20 -fold [25, 26, 39, 40]. One consequence of HER2 overexpression in epithelial cells is hyperproliferation $[25,26]$, which requires an increase in FA synthesis in order to provide building materials for new membranes and lipid rafts $[1-3,15]$. This requirement to lipogenesis for survival and proliferation may represent a target treatment in HER2-driven oncogenesis [1$3,15]$. Experimental and clinical studies have shown that the early stages of tumorigenesis in HER2-overexpressing breast cancer cells are associated with increased activation of the FASN-mediated synthesis of palmitic acid, which is often used to form lipid rafts $[1-3,5,15,19,41,42]$. In the present study, HER2 overexpression was accompanied by an increase 
in FASN protein activation, in parallel with the increased expression of DGAT, a gene that encodes an enzyme involved in the final step of triglyceride synthesis [43]. Thus, breast cancer cells that overexpress HER2 and have increased FASN activity may sustain their proliferation and avoid lipotoxicity by converting and storing excess palmitate as triglycerides.

The increase in DGAT expression was accompanied by an increase in expression levels of FAT/CD36 and $F A B P 4$, which encode proteins involved in the uptake and transport of FAs. These processes facilitate the synthesis of cellular membranes during cell proliferation suggesting that HER2-overexpressing breast cancer cells alter their metabolism to improve triglyceride synthesis and lipid uptake/incorporation for cell proliferation [1-3]. These findings suggest that a lipogenic phenotype is required and possibly induced by HER2 overexpression and the observed increase in FASN activation comprises only one part of a much larger lipogenic program in such cells.

Although the exact mechanism linking HER2 signaling with lipogenesis remains unknown, accumulating evidence indicates that activation of PPAR $\gamma$ via the mTOR pathway may regulate this process [1, 2, 31, 33-35]. According to our results, the mTORC1 activity (component of the mTOR pathway) in $\mathrm{HB} 4 \mathrm{aC} 5.2$ cells was low suggesting that PPAR $\gamma$ may be regulated through a pathway other than mTOR. Indeed, this lipogenic program required for oncogenic transformation in $\mathrm{HB} 4 \mathrm{aC} 5.2$ cells was not found to be coordinated by PPAR $\gamma$ activity because the blockage of its activity did not alter the expression of the lipogenic genes assayed in these cells. This finding raises the possibility that HER2 overexpression may employ another mechanism to maintain or generate the lipogenic phenotype $[33,34]$. Based on the present findings, DEPTOR may be a potential mediator.

DEPTOR is the main inhibitor of the mTOR pathway and may regulate the lipogenesis process $[33,34]$. In adipocytes, $D E P T O R$ expression promotes adipogenesis, whereas inhibition of DEPTOR blocks this process [33]. In animal models, $D E P T O R$ overexpression is responsible for the accumulation of white adipose tissue, and in humans, it is associated with some degree of obesity [33].

Experimental evidence suggests that DEPTOR is a potent activator of Akt-mediated survival pathways [33, 34]. For example, when DEPTOR is overexpressed, mTORC1 activity is reduced and the PI3K/mTORC2/Akt pathway is activated via release of the inhibitory feedback that mTORC1 imposes on mTORC2 [32]. Interestingly, this indirect mode of Akt protein activation appears to be important for the viability of thyroid carcinoma and multiple myeloma cells [35]. DEPTOR overexpression and reduced $\mathrm{mTORC1}$ complex activity have been detected in approximately $28 \%$ of patients with multiple myeloma, and these patients had lower survival rates [35]. Experimentally, DEPTOR overexpression has been shown to reduce protein synthesis and cell growth in multiple myeloma cells, while activating survival signals from PI3K/Akt proteins. DEPTOR downregulation has also been shown to promote cell death [35].

We previously reported that HER2 overexpression in HB4aC5.2 cells is accompanied by hyperactivation of Akt [15]. In the present study, a significant increase in DEPTOR expression and decreases in the expression levels of mTORC1 pathway members (i.e., p70S6K and SREBP1) were observed in $\mathrm{HB} 4 \mathrm{aC} 5.2$ cells. It may be that the increase in DEPTOR expression provides an important oncogenic advantage for HB4aC5.2 cells. DEPTOR may help regulate lipogenesis to facilitate proliferation and may enhance Akt activation in favor of cell survival. Akt can promote cell survival by various mechanisms, including regulation of transcription factors other than PPAR $\gamma$ [44, 45]. As an Akt activator [35], DEPTOR may enhance the expression of lipogenic genes that are targeted not only by PPAR $\gamma$ but also by other transcription factors. This explanation would account for the observed increase in lipogenic gene expression in HER2overexpressing cells while PPAR $\gamma$ activity was not detected.

Overall, the present results show that the oncogenic transformation of $\mathrm{HB} 4 \mathrm{aC} 5.2$ cells by HER 2 overexpression appears to promote a lipogenic environment conducive to cell proliferation and cell survival. Furthermore, this environment may be potentially dependent on DEPTOR overexpression. Accordingly, inhibitors of lipogenic enzymes, modulators of DEPTOR gene expression, and FA supply could impair HER2-mediated oncogenesis.

Several reports have indicated that omega-3 polyunsaturated FAs, such as DHA, can act as efficient anti-HER2 therapeutics $[2,15,46]$. Previous studies have largely attributed the DHA sensitivity of HER2-positive cells to the ability of this FA to suppress HER2 expression or HER2-mediated pathways by different mechanisms (e.g., lipid raft disruption). However, it is possible that the supplementation of highly lipogenic HER2-positive cells with FAs other than palmitate could trigger the generation of reactive oxygen species and cell death $[1,2,15,46]$. In the present study, DHA treatment of the HB4aC5.2 cells led to a decrease in DGAT expression and an induction of apoptosis. These findings indicate the diminished ability of these cells to mediate the nontoxic accumulation of lipids in their triglyceride form.

Interestingly, the increased expression levels of FAT/ CD36 and FABP4 that were observed in HB4aC5.2 cells were maintained after DHA treatment of these cells. It is possible that these cells were able to capture and transport DHA for cell membrane formation. Such preferential use of DHA would inhibit cell survival and proliferation, due to alterations in the formation of cell membrane lipid rafts [47-49]. Previously, we reported that DHA treatment of HB4aC5.2 cells increased DHA and decreased palmitic acid percentages in cell membranes [15]. These changes were observed concomitantly with a decrease in the number of lipid rafts, which, in turn, may have impaired HER2mediated signaling [15]. This possibility was supported by the simultaneous decrease in activation of the Akt and ERK1/2 proteins [15]. In the present study, DHA treatment led to decreased activity of the FASN protein and lower expression levels of DGAT and DEPTOR. Besides, the DHA treatment plus trastuzumab was able to increase cell death percentage, in $\mathrm{HB} 4 \mathrm{aC} 5.2$ cells, when compared with DHA and trastuzumab alone.

Taken together, these data support the possibility that the mechanism responsible for DHA-related toxicity in $\mathrm{HB} 4 \mathrm{aC} 5.2$ cells includes a disturbance of the lipogenic genetic 
program. This disturbance may be mediated, at least in part, by DEPTOR and is distinct from trastuzumab, which seems to disturb FASN activity by different mechanisms. The cytotoxic pathways that are involved seem to be complementary, to improve cell death only in HER2-overexpressing HB4aC5.2 cells. Moreover, DHA appears to increase the sensitivity of cells to death by modulating a HER2-driven lipogenic genetic program. These findings support the use of DHA as a candidate therapeutic agent for minimizing HER2mediated oncogenesis in breast cancer cells by disturbing a $\operatorname{PPAR} \gamma$-independent lipogenic phenotype associated with HER2 overexpression.

One limitation of the present study design is its specificity. For example, the HB4aC5.2 cell line was designed to overexpress HER2. These cells exhibited noninvasive and proliferative characteristics and expressed luminal epithelial markers. Consequently, the present results should be analyzed with caution when extrapolated to more complex models or other types of cells representing different breast cancer tumor stages. Additionally, the results provided in this study are valid only for DHA, which may have distinct or different antitumoral effects than other omega-3 fatty acids, such as eicosapentaenoic acid (EPA), and omega- 6 fatty acids, such as arachidonic acid (AA) [50]. Indeed, it is widely recognized that $\mathrm{DHA}$ reduce and $\mathrm{AA}$ increase the risk of breast cancer in experimental and clinical studies [50-53]. However, it is noteworthy that the opposite effects between these FA also seem to extend to the cellular lipogenesis [23, 24, 54, 55]. Some authors have shown that DHA suppress adiposity in rodents and block adipogenesis in many adipocyte cell lines $[23,24]$, while AA is associated with increase of adipogenesis $[54,55]$. According to our results, the DHA antitumoral effect was accompanied by cellular lipogenesis decrease. In this scenario, an important question emerges: Is it possible that AA effect toward tumorigenesis [50-53] might be associated with its capacity to increase cellular lipogenesis $[54,55]$ ? Moreover, are tumor lipogenic phenotype and FA (DHA and AA) effects associated? From a clinical perspective, considering that dietary fat is part of modifiable risk of breast cancer, further studies should be conducted to evaluate the role of different FA in lipogenesis and breast cancer progression.

Together, our data demonstrate that an oncogenic transformation of HER2-expressing breast cancer cells supercharges cell lipogenesis via coexpression of various genes involved in the synthesis, uptake, transport, and storage of FAs. DHA treatment disturbs this lipogenic state by inducing cell death and increasing the action of trastuzumab. Therefore, DHA may represent a useful tool for controlling the aberrant signaling triggered by HER2. Nutritional interventions may constitute a new approach for improving conventional therapies, without adversely affecting patient quality of life. In particular, DHA supplementation in combination with other drugs, such as inhibitors of HER2 (trastuzumab), should be explored as a treatment strategy for breast cancer.

\section{Conflict of Interests}

The authors have no potential conflict of interests to disclose.

\section{Authors' Contribution}

Graziela Rosa Ravacci was responsible for the conception, design, acquisition, and analysis of data, interpretation of the results, and drafting of the paper. Maria Mitzi Brentani contributed to the conception and design of the research, reviewing of the paper, and interpretation of the results. Tharcisio Citrângulo Tortelli was responsible for the acquisition and analysis of data and reviewing of the paper. Raquel Suzana M. M. Torrinhas, Jéssica Reis Santos, and Angela Flávia Logullo participated in the writing of the paper. Dan Linetzky Waitzberg contributed to the conception of the research and reviewing of the paper.

\section{Acknowledgments}

The authors are grateful to Michael J. O'Hare for the gift of the cell lines and to Professor José Ernesto Belizário for the gift of trastuzumab. The authors thank the Fundação de Amparo à Pesquisa do Estado de São Paulo (FAPESP, Brazil) for their financial support of this study (Process no. 2009/52244-5). This paper was funded by FAPESP (Fundação de Amparo à Pesquisa, Brazil) Process no. 2009/52244-5.

\section{References}

[1] J. A. Menendez and R. Lupu, "Fatty acid synthase and the lipogenic phenotype in cancer pathogenesis," Nature Reviews Cancer, vol. 7, no. 10, pp. 763-777, 2007.

[2] J. A. Menendez, "Fine-tuning the lipogenic/lipolytic balance to optimize the metabolic requirements of cancer cell growth: molecular mechanisms and therapeutic perspectives," Biochimica et Biophysica Acta-Molecular and Cell Biology of Lipids, vol. 1801, no. 3, pp. 381-391, 2010.

[3] M. Hilvo, C. Denkert, L. Lehtinen et al., "Novel theranostic opportunities offered by characterization of altered membrane lipid metabolism in breast cancer progression," Cancer Research, vol. 71, no. 9, pp. 3236-3245, 2011.

[4] M. T. E. Montales, O. M. Rahal, H. Nakatani, T. Matsuda, and R. C. M. Simmen, "Repression of mammary adipogenesis by genistein limits mammosphere formation of human MCF-7 cells," Journal of Endocrinology, vol. 218, no. 1, pp. 135-149, 2013.

[5] C. Nieva, M. Marro, N. Santana-Codina, S. Rao, D. Petrov, and A. Sierra, "The lipid phenotype of breast cancer cells characterized by Raman microspectroscopy: towards a stratification of malignancy," PLoS ONE, vol. 7, no. 10, Article ID e46456, 2012.

[6] S. M. Tovey, S. Brown, J. C. Doughty, E. A. Mallon, T. G. Cooke, and J. Edwards, "Poor survival outcomes in HER2-positive breast cancer patients with low-grade, node-negative tumours," British Journal of Cancer, vol. 100, no. 5, pp. 680-683, 2009.

[7] J. Arribas, J. Baselga, K. Pedersen, and J. L. Parra-Palau, "p95HER2 and breast cancer," Cancer Research, vol. 71, no. 5, pp. 1515-1519, 2011.

[8] A. Bollig-Fischer, M. Dziubinski, A. Boyer, R. Haddad, C. N. Giroux, and S. P. Ethier, "HER-2 signaling, acquisition of growth factor independence, and regulation of biological networks associated with cell transformation," Cancer Research, vol. 70, no. 20, pp. 7862-7873, 2010.

[9] R. Ghosh, A. Narasanna, S. E. Wang et al., “Trastuzumab has preferential activity against breast cancers driven by HER2 homodimers," Cancer Research, vol. 71, no. 5, pp. 1871-1882, 2011. 
[10] J. C. Singh, K. Jhaveri, and F. J. Esteva, "HER2-positive advanced breast cancer: optimizing patient outcomes and opportunities for drug development," British Journal of Cancer, vol. 111, pp. 1888-1898, 2014.

[11] Y. Wu, X. Shang, M. Sarkissyan, D. Slamon, and J. V. Vadgama, "FOXO1A is a target for HER2-overexpressing breast tumors," Cancer Research, vol. 70, no. 13, pp. 5475-5485, 2010.

[12] T. Ichikawa, F. Sato, K. Terasawa et al., "Trastuzumab produces therapeutic actions by upregulating miR-26a and miR-30b in breast cancer cells," PLoS ONE, vol. 7, no. 2, Article ID e31422, 2012.

[13] A. B. Zelnak, P. Nikolinakos, J. Srinivasiah et al., "High pathologic complete response in Her2-positive, early-stage breast cancer to a novel nonanthracycline neoadjuvant chemotherapy," Clinical Breast Cancer, vol. 15, no. 1, pp. 31-36, 2015.

[14] 2014, http://www.gene.com/download/pdf/herceptin_prescribing.pdf.

[15] G. R. Ravacci, M. M. Brentani, T. Tortelli et al., "Lipid raft disruption by docosahexaenoic acid induces apoptosis in transformed human mammary luminal epithelial cells harboring HER-2 overexpression," Journal of Nutritional Biochemistry, vol. 24, no. 3, pp. 505-515, 2013.

[16] P. Nagy, G. Vereb, Z. Sebestyén et al., "Lipid rafts and the local density of ErbB proteins influence the biological role of homoand heteroassociations of ErbB2," Journal of Cell Science, vol. 115, no. 22, pp. 4251-4262, 2002.

[17] M.-M. Mocanu, Z. Fazekas, M. Petrás et al., "Associations of ErbB2, betal-integrin and lipid rafts on Herceptin (trastuzumab) resistant and sensitive tumor cell lines," Cancer Letters, vol. 227, no. 2, pp. 201-212, 2005.

[18] D. C. Márquez, H.-W. Chen, E. M. Curran, W. V. Welshons, and R. J. Pietras, "Estrogen receptors in membrane lipid rafts and signal transduction in breast cancer," Molecular and Cellular Endocrinology, vol. 246, no. 1-2, pp. 91-100, 2006.

[19] Q. Jin, L. X. Yuan, D. Boulbes et al., "Fatty acid synthase phosphorylation: a novel therapeutic target in HER2-overexpressing breast cancer cells," Breast Cancer Research, vol. 12, article R96, 2010.

[20] S. Hardy, Y. Langelier, and M. Prentki, "Oleate activates phosphatidylinositol 3-kinase and promotes proliferation and reduces apoptosis of MDA-MB-231 breast cancer cells, whereas palmitate has opposite effects," Cancer Research, vol. 60, no. 22, pp. 6353-6358, 2000.

[21] R. T. Brookheart, C. I. Michel, and J. E. Schaffer, "As a matter of fat," Cell Metabolism, vol. 10, no. 1, pp. 9-12, 2009.

[22] A. Kourtidis, R. Srinivasaiah, R. D. Carkner, M. J. Brosnan, and D. S. Conklin, "Peroxisome proliferator-activated receptor$\gamma$ protects ERBB2-positive breast cancer cells from palmitate toxicity," Breast Cancer Research, vol. 11, article R16, 2009.

[23] H. N. Bagley, Y. Wang, M. S. Campbell, X. Yu, R. H. Lane, and L. A. Joss-Moore, "Maternal docosahexaenoic acid increases adiponectin and normalizes IUGR-induced changes in rat adipose deposition," Journal of Obesity, vol. 2013, Article ID 312153, 7 pages, 2013.

[24] N. Siriwardhana, N. S. Kalupahana, M. Cekanova, M. LeMieux, B. Greer, and N. Moustaid-Moussa, "Modulation of adipose tissue inflammation by bioactive food compounds," Journal of Nutritional Biochemistry, vol. 24, no. 4, pp. 613-623, 2013.

[25] R. A. Harris, T. J. Eichholtz, I. D. Hiles, M. J. Page, and M. J. O'Hare, "New model of ErbB-2 over-expression in human mammary luminal epithelial cells," International Journal of Cancer, vol. 80, no. 3, pp. 477-484, 1999.
[26] J. F. Timms, S. L. White, M. J. O’Hare, and M. D. Waterfield, "Effects of ErbB-2 overexpression on mitogenic signalling and cell cycle progression in human breast luminal epithelial cells," Oncogene, vol. 21, no. 43, pp. 6573-6586, 2002.

[27] J. M. Seargent, E. A. Yates, and J. H. Gill, "GW9662, a potenteantagonista of PPAR gamma, inhibits growth of breast tumour cells and promotes the anticancer effects of the PPAR gamma agonist rosiglitazone, independently of PPAR gamma activation," British Journal of Pharmacology, vol. 143, no. 8, pp. 933-937, 2004.

[28] R. A. Siddiqui, L. J. Jenski, K. Neff, K. Harvey, R. J. Kovacs, and W. Stillwell, "Docosahexaenoic acid induces apoptosis in Jurkat cells by a protein phosphatase-mediated process," Biochimica et Biophysica Acta-Molecular Cell Research, vol. 1499, no. 3, pp. 265-275, 2001.

[29] T. Martins de Lima, M. F. Cury-Boaventura, G. Giannocco, M. T. Nunes, and R. Curi, "Comparative toxicity of fatty acids on a macrophage cell line (J774)," Clinical Science, vol. 111, no. 5, pp. 307-317, 2006.

[30] A. Kourtidis, R. Jain, R. D. Carkner, C. Eifert, M. J. Brosnan, and D. S. Conklin, "An RNA interference screen identifies metabolic regulators NR1D1 and PBP as novel survival factors for breast cancer cells with the ERBB2 signature," Cancer Research, vol. 70, no. 5, pp. 1783-1792, 2010.

[31] M. Laplante and D. M. Sabatini, "An emerging role of mTOR in lipid biosynthesis," Current Biology, vol. 19, no. 22, pp. R1046R1052, 2009.

[32] R. Zoncu, A. Efeyan, and D. M. Sabatini, "mTOR: fom growth signal integration to cancer, diabetes and ageing," Nature Reviews Molecular Cell Biology, vol. 12, no. 1, pp. 21-35, 2011.

[33] M. Laplante, S. Horvat, W. T. Festuccia et al., "Deptor cellautonomously promotes adipogenesis, and its expression is associated with obesity," Cell Metabolism, vol. 16, no. 2, pp. 202$212,2012$.

[34] Z. Wang, J. Zhong, H. Inuzuka et al., "An evolving role for DEPTOR in tumor development and progression," Neoplasia, vol. 14, no. 5, pp. 368-375, 2012.

[35] T. R. Peterson, M. Laplante, C. C. Thoreen et al., "DEPTOR is an mTOR inhibitor frequently overexpressed in multiple myeloma cells and required for their survival," Cell, vol. 137, no. 5, pp. 873886, 2009.

[36] N. A. O’Brien, K. McDonald, L. Tong et al., “Targeting $\mathrm{PI} 3 \mathrm{~K} / \mathrm{mTOR}$ overcomes resistance to HER2-targeted therapy independent of feedback activation of AKT," Clinical Cancer Research, vol. 20, no. 13, pp. 3507-3520, 2014.

[37] G. Murali, C. V. Desouza, M. E. Clevenger, R. Ramalingam, and V. Saraswathi, "Differential effects of eicosapentaenoic acid and docosahexaenoic acid in promoting the differentiation of 3T3L1 preadipocytes," Prostaglandins Leukotrienes and Essential Fatty Acids, vol. 90, no. 1, pp. 13-21, 2014.

[38] M. Rossmeisl, D. Medrikova, E. M. Van Schothorst et al., "Omega-3 phospholipids from fish suppress hepatic steatosis by integrated inhibition of biosynthetic pathways in dietary obese mice," Biochimica et Biophysica Acta-Molecular and Cell Biology of Lipids, vol. 1841, no. 2, pp. 267-278, 2014.

[39] E. Arriola, C. Marchio, D. S. P. Tan et al., "Genomic analysis of the HER2/TOP2A amplicon in breast cancer and breast cancer cell lines," Laboratory Investigation, vol. 88, no. 5, pp. 491-503, 2008.

[40] I. Busmanis, F. Feleppa, A. Jones et al., "Analysis of cerbb2 expression using a panel of 6 commercially available antibodies," Pathology, vol. 26, no. 3, pp. 261-267, 1994. 
[41] C. Yan, H. Wei, Z. Minjuan et al., "The mTOR inhibitor rapamycin synergizes with a fatty acid synthase inhibitor to induce cytotoxicity in ER/HER2-positive breast cancer cells," PLoS ONE, vol. 9, no. 5, Article ID e97697, 2014.

[42] R. Porta, A. Blancafort, G. Casòliva et al., "Fatty acid synthase expression is strongly related to menopause in early-stage breast cancer patients," Menopause, vol. 21, no. 2, pp. 188-191, 2014.

[43] C.-L. E. Yen, S. J. Stone, S. Koliwad, C. Harris, and R. V. Farese Jr., "DGAT enzymes and triacylglycerol biosynthesis," Journal of Lipid Research, vol. 49, no. 11, pp. 2283-2301, 2008.

[44] A. Bielli, M. G. Scioli, P. Gentile et al., "Adult adipose-derived stem cells and breast cancer: a controversial relationship," SpringerPlus, vol. 3, no. 1, pp. 1-10, 2014.

[45] E. Hinoi, T. Iezaki, H. Fujita et al., "PI3K/Akt is involved in brown adipogenesis mediated by growth differentiation factor-5 in association with activation of the Smad pathway," Biochemical and Biophysical Research Communications, vol. 450, no. 1, pp. 255-260, 2014.

[46] Z. Zou, C. Bidu, S. Bellenger, M. Narce, and J. Bellenger, "N3 polyunsaturated fatty acids and HER2-positive breast cancer: interest of the fat- 1 transgenic mouse model over conventional dietary supplementation," Biochimie, vol. 96, no. 1, pp. 22-27, 2014.

[47] P. D. Schley, D. N. Brindley, and C. J. Field, “(n-3) PUFA alter raft lipid composition and decrease epidermal growth factor receptor levels in lipid rafts of human breast cancer cells," Journal of Nutrition, vol. 137, no. 3, pp. 548-553, 2007.

[48] K. R. Rogers, K. D. Kikawa, M. Mouradian et al., "Docosahexaenoic acid alters epidermal growth factor receptor-related signaling by disrupting its lipid raft association," Carcinogenesis, vol. 31, no. 9, pp. 1523-1530, 2010.

[49] P. A. Corsetto, A. Cremona, G. Montorfano et al., "Chemicalphysical changes in cell membrane microdomains of breast cancer cells after omega-3 PUFA incorporation," Cell Biochemistry and Biophysics, vol. 64, no. 1, pp. 45-59, 2012.

[50] S. Abel, S. Riedel, and W. C. A. Gelderblom, "Dietary PUFA and cancer," Proceedings of the Nutrition Society, vol. 73, no. 3, pp. 361-367, 2014.

[51] H.-M. Su, P.-H. Hsieh, and H.-F. Chen, "A maternal high n6 fat diet with fish oil supplementation during pregnancy and lactation in rats decreases breast cancer risk in the female offspring," Journal of Nutritional Biochemistry, vol. 21, no. 11, pp. 1033-1037, 2010.

[52] P. Bougnoux, N. Hajjaji, and C. Couet, "The lipidome as a composite biomarker of the modifiable part of the risk of breast cancer," Prostaglandins Leukotrienes and Essential Fatty Acids, vol. 79, no. 3-5, pp. 93-96, 2008.

[53] L. Hilakivi-Clarke, I. Onojafe, M. Raygada, E. Cho, R. Clarke, and M. E. Lippman, "Breast cancer risk in rats fed a diet high in n-6 polyunsaturated fatty acids during pregnancy," Journal of the National Cancer Institute, vol. 88, no. 24, pp. 1821-1827, 1996.

[54] H. Vaidya and S. K. Cheema, "Arachidonic acid has a dominant effect to regulate lipogenic genes in 3T3-L1 adipocytes compared to omega-3 fatty acids," Food \& Nutrition Research, vol. 59, Article ID 25866, 2015.

[55] F. Zhang, Y. Chen, J. Long, L. Dong, Y. Wang, and Y. Chen, "Dietary fatty acids affect lipid metabolism and estrogen receptor expression in $\mathrm{N}$-methyl-N-nitrosourea-induced rat mammary cancer model," Clinical Laboratory, vol. 61, no. 3-4, pp. 389-395, 2015. 


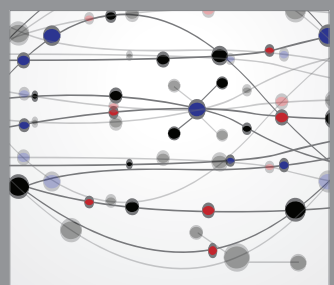

The Scientific World Journal
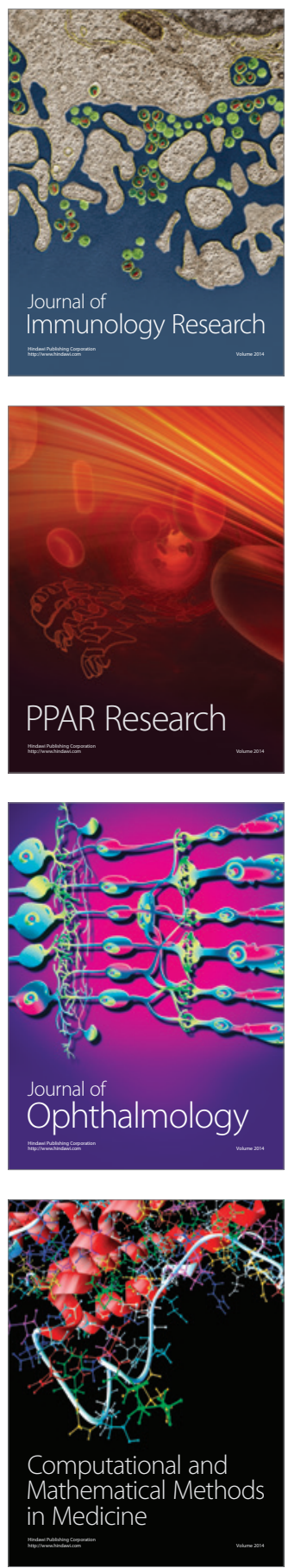

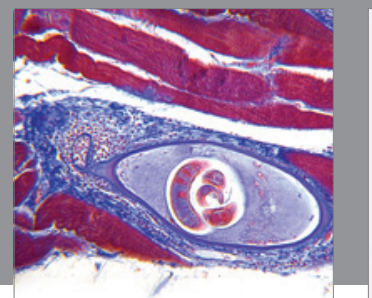

Gastroenterology

Research and Practice
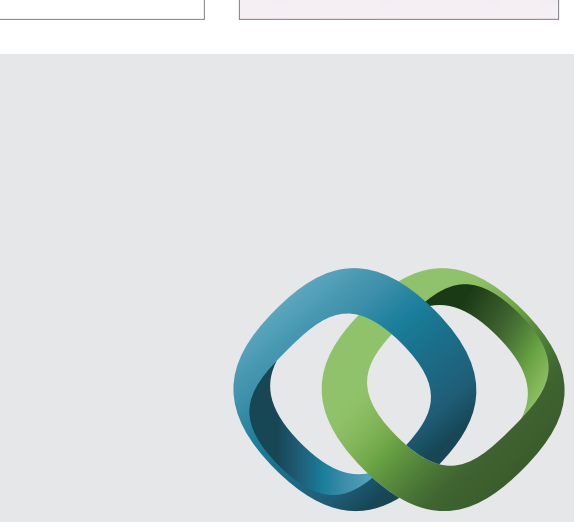

\section{Hindawi}

Submit your manuscripts at

http://www.hindawi.com
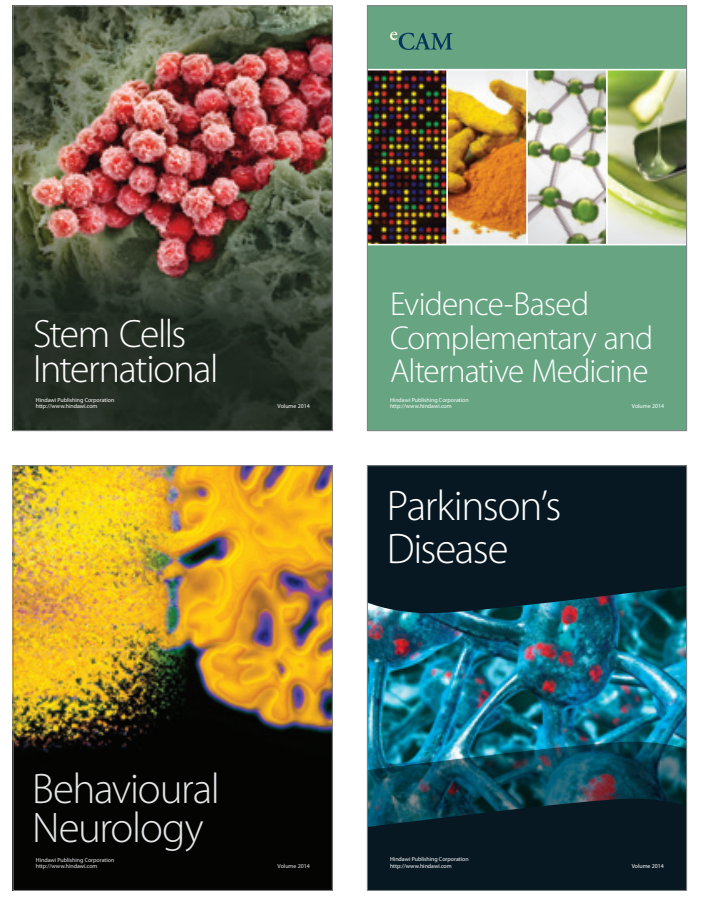
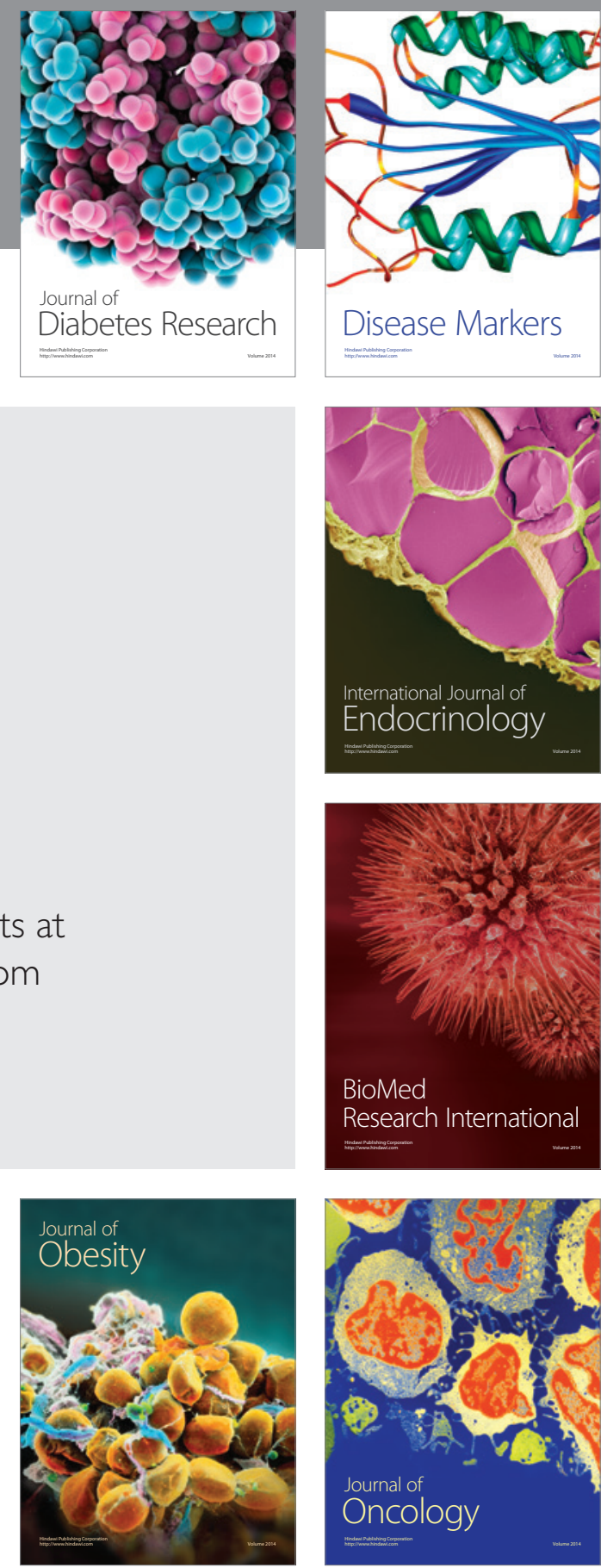

Disease Markers
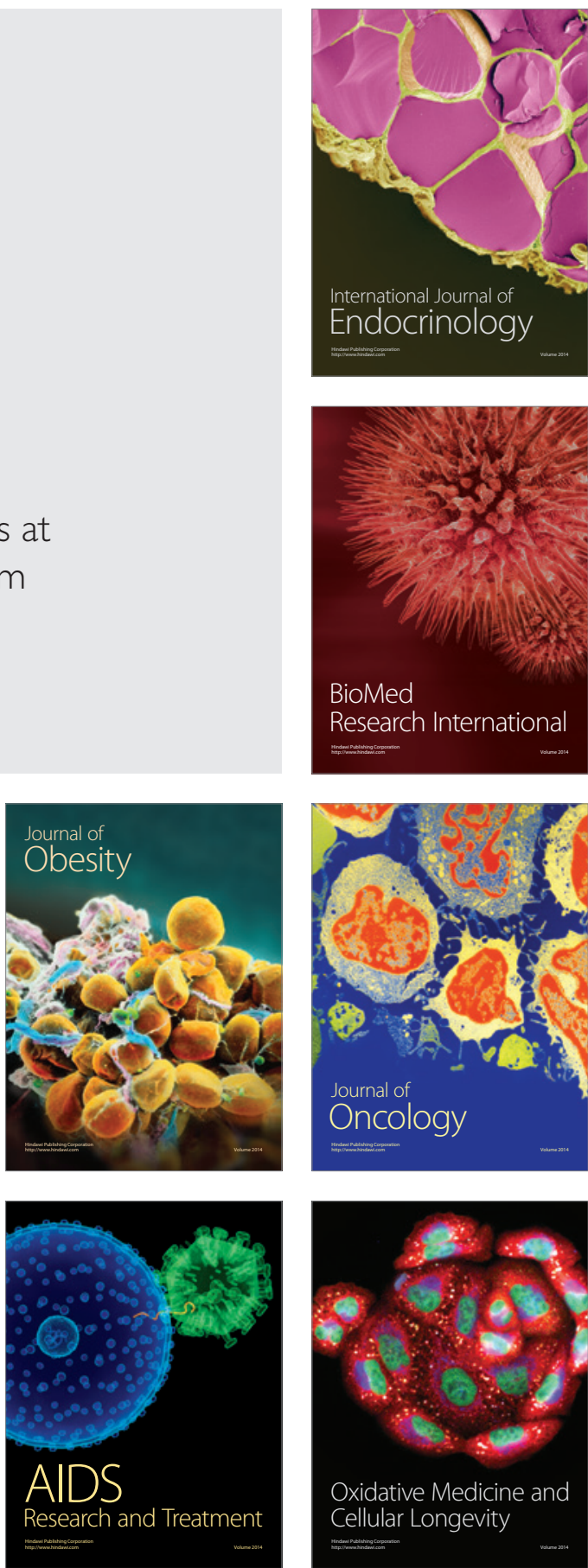